\title{
Adenoid Kistik Karsinom: Vaka Raporu
}

\author{
Adenoid Cystic Carcinoma: Case Report
}

\author{
Rıdvan Karakurt, Derya İçöz
}

Selçuk Üniversitesi Diş Hekimliği Fakültesi, Radyoloji Anabilim Dalı, Konya, Türkiye

\begin{abstract}
Özet: Adenoid kistik karsinoma (AKK), tükrük bezlerinin ikinci en sık malign epitelyal tümörüdür. Bu vaka sunumunun amacı parotis bezinde görülen bir solid AKK vakasını sunmaktı. Kliniğimize sağ mandibula posterior bölgede şişlik, ağrı ve parestezi şikayetiyle 69 yaşında erkek hasta başvurmuştur. Klinik muayenede mandibular molar bölgede ülserasyonlu alanlar görülmüş̧ür. Submandibuler ve servikal lenfadenopatiler tespit edilmiş, bukkal mukozada ekspansif karakterde bir kitle tespit edilmiștir. Panoramik radyografta sağ ramus mandibulada radyolusent bir lezyon izlenmiş, konik ışınlı bilgisayarlı tomografide (KIBT) lezyonun kemikte destrüksiyona yol açtığı tespit edilmiştir. Biyopsi sonucunda AKK olduğu rapor edilip eksizyonu önerilmiştir. Erken tanı ve tedavi sağ kalım ve uzak bölgelere metastazı engellemek açısından çok önemlidir. Bu nedenle doğru tanı ve değerlendirme bu tip vakaların tedavi başarısını etkileyecektir.
\end{abstract}

Anahtar Kelimeler: Adenoid Kistik Karsinoma; Mandibula; Parotis; Konik Işınlı Bilgisayarlı Tomografi; Panoramik radyografi

Abstract: Adenoid cystic carcinoma (ACC) is the second most common malignant epithelial tumor of the salivary glands. The aim of this case report was to present a solid ACC case seen in the parotid gland. A 69-year-old male patient was admitted to our clinic with complaints of swelling, pain and paraesthesia in the posterior right mandible. In clinical examination mandibular ulcerated areas were observed. Submandibular and cervical lymphadenopathies and an expansive mass were detected in the buccal mucosa. In panoramic radiography, a radiolucent lesion was observed in the right ramus mandible, and in cone beam computed tomography(CBCT) it was determined that lesion caused bone destruction. As result of the biopsy, it was reported as ACC and excision was recommended. Early diagnosis and treatment is very important in terms of survival and prevention of metastasis to distant areas. Therefore, accurate diagnosis and evaluation will affect the treatment success.

Keywords: Adenoid Cystic Carcinoma; Mandible; Parotid; Cone Beam Computed Tomography; Panoramic radiography

ORCID ID of the authors: R.K. 0000-0003-0775-2363, D.İ. 0000-0001-8043-288X 


\section{Giriş}

Adenoid kistik karsinoma (AKK), tükürük bezlerinin nadir görülen bir malign neoplazmıdır (1). Baş-boyun bölgesinde görülen malign neoplazilerin \%1'inden daha azını oluşturmakla birlikte minör tükürük bezlerinin en yaygın, majör tükürük bezlerinin ise ikinci en sik görülen malign tümörüdür (2).

Tükürük bezlerinde görülen bütün tümörlerin $\% 80$ 'ine parotis bezinde rastlanmaktadır. Bununla beraber minör tükürük bezi tümörlerinin $\% 65{ }^{\prime} i$ malign karakterde olmasına rağmen, parotiste görülen tümörlerin \%80'i benign karakterlidir. Parotiste görülen malign karakterli lezyon tipleri; mukoepidermoid karsinom ve AKK'dır (3). AKK submandibuler tükürük bezi, sublingual tükürük bezi ve minör tükürük bezlerinin en yaygın görülen malign tümörü olmasına rağmen, parotid kanserlerinin yalnızca \%15'ini oluşturmaktadır (1). Özellikle kadınlarda ve çoğunluğu erişkinlerde, yaşamın 5. ve 6. dekatlarında görülmektedir (3-5).

AKK yavaş büyüyen fakat agresif karakterli, rekürrens kapasitesi yüksek bir neoplazmdır (6). Uzun süreli klinik seyri ve uzak metastazların geç başlaması ile bilinmektedir. Uzak metastazlar ve rejyonel lenf nodlarına yayılım, genellikle hastalığın geç evrelerinde, tan1 konulmasindan uzun yillar sonra ortaya çıkabilmektedir. Uzak metastazlarda genellikle tutulum organı akciğerler olmak üzere kemik, karaciğer ve beyin metastazları da rapor edilmiştir (7). Komşu yapılara yayılımı oldukça agresiftir ve hematojen yolla yayılım lenfatik yayılımdan daha yaygındır (1). Perinöral invazyon karakteristiktir ve olguların \%60'ından fazlasında görülmektedir (8). AKK'nin histolojik alt tipleri; kribriform, tübüler ve solid tiplerdir. Bu tipler ayrı ayrı olabildiği gibi aynı tümörde farklı tiplerin bulunabilmesi de söz konusu olabilmektedir. Solid alt tipi en agresif seyirli olandır (9). En s1k görülen histolojik alt tipi ise kribriformdur (4).

Cerrahi planlamada bilgisayarlı tomografi (BT) ve manyetik rezonans görüntüleme (MRG) özellikle submukozal genişleme ve perinöral yayılım varlığında, klinik olarak değerlendirmenin zor olduğu durumlarda oldukça faydalı görüntüleme yöntemleridir. $\mathrm{Bu}$ lezyonlar genellikle belirgin olmayan ve infiltratif sinırlara sahiptir (7). Tedavisi geniş sınırlı rezeksiyon şeklindedir ve postoperatif nükslere karşı postoperatif radyoterapi uygulanabilmektedir $(3,7)$. Vakaların lokal agresif özelliği, rekürrensinin yüksek olmas1 ve tanı konmasinda uzun yıllar sonra uzak metastaz yapma olasıllığından dolayı başlangıç tedaviden y1llar sonra bile fetal olabilmektedir. $\mathrm{Bu}$ nedenle bu neoplazmların uzun süreli takibi önemlidir (4).

$\mathrm{Bu}$ vaka raporunda sağ bukkal mukoza ve mandibuler posterior bölgede izlenen ve kemikte destrüksiyona sebep olmuş, histopatolojik olarak AKK tanısı konmuş bir olgunun sunulması amaçlanmıştır.

\section{Olgu Bildirimi}

Kliniğimize sağ mandibula posterior bölge bukkal mukozada şişlik, ağrı ve parestezi şikayetiyle 69 yaşında erkek hasta başvurmuştur. Hasta bu şişliğin birkaç yıldır mevcut olduğunu, ancak giderek büyüklüğünün arttığını belirtmiştir (Resim 1).

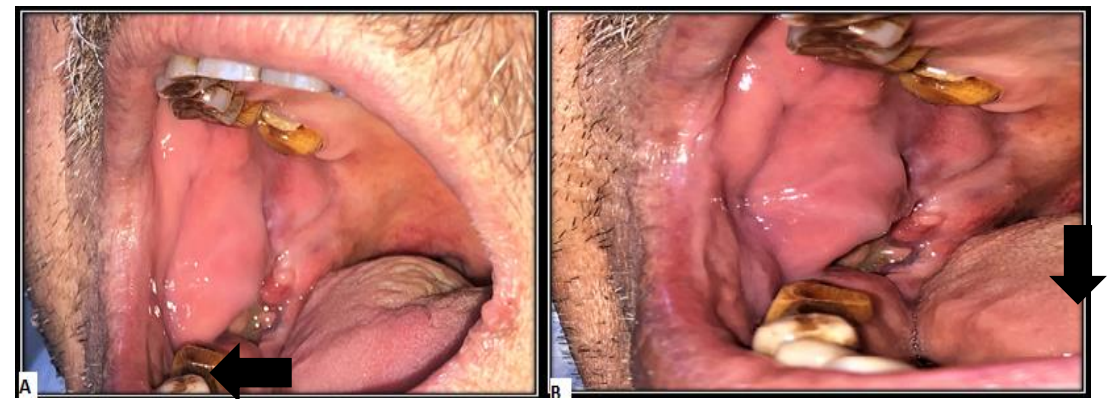

Resim 1. İntraoral muayene sırasında izlenen bukkal mukozadaki şişlik (A) ve alveolar kretteki ülsere alan (B). 


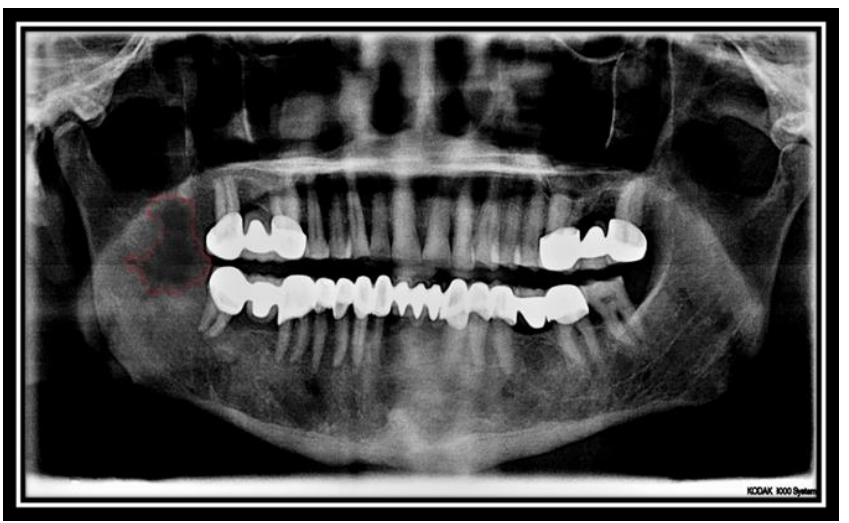

Resim 2. Panoramik radyografta sağ retromolar bölgede, ramus mandibula üzerinde düzensiz şekilli radyolüsent lezyon.

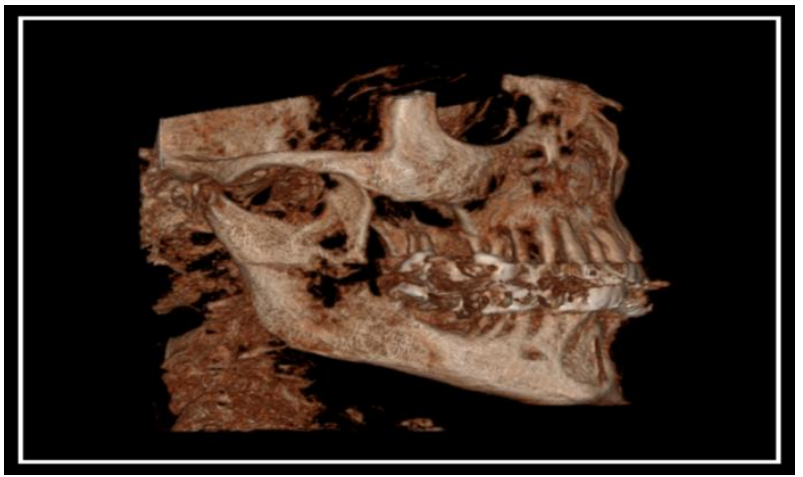

Resim 3. Mandibular ramustaki kemik yıkımının 3D modeldeki görüntüsü.
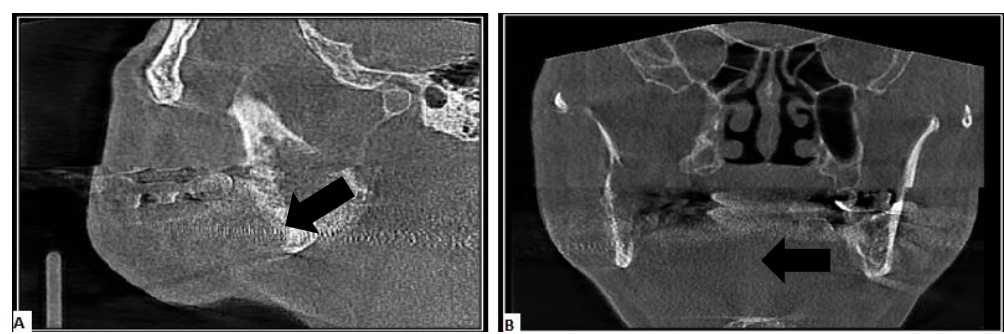

Resim 4. Lezyon ve sebep olduğu kemik destrüksyonunun sagittal (A)ve koronal kesitteki (B) BT görüntüsü

Hastadan alınan medikal ananmezde herhangi bir sistemik hastalığının olmadığ 1 öğrenilmiştir. Yapılan intraoral ve ekstraoral muayenede mandibuler molar bölgede ülserasyonlu bir bölge, submandibular ve servikal lenfadenopatiler tespit edilmiş, bukkal mukozada molar diş bölgesinden angulus mandibulaya doğru ekspansif karakterde, palpasyonda sert kıvamlı bir kitle tespit edilmiştir (Resim1).

Radyografik muayenede ise hastadan alınan panoramik radyografta sağ taraf mandibula ramus bölgesinde radyolusent bir lezyon izlenmiştir (Resim 2). Patolojik özelliklerin daha iyi lokalize edilmesi ve tanımlanması için alınan konik 1şınlı bilgisayarlı tomografide (KIBT) mandibuler ramus bölgesinde mandibuler kanalla yakın ilişkili, sagittal kesitte en geniş sınırları $32 \times 18 \mathrm{~mm}$ boyutlarında olan amorf kitle izlenmiş (Resim 4), ayrica lezyonun bukkal ve lingual kortikal kemikte destrüksiyona yol açtığ 1 tespit edilmiştir (Resim 3). Lezyon, bulguları nedeniyle maligniteyi düşündürmüştür. $\mathrm{Bu}$ şüpheyle yönlendirilen hastanın biyopsisinde tükrük bezi orjinli bir malignite olan adenoid kistik karsinom olduğu rapor edilmiş ve hasta lezyonun eksizyonu için yönlendirilmiştir. Nüks etme potansiyeline karşı hastaya uzun dönem takip önerilmiştir. 


\section{Tartışma}

AKK, ilk olarak 1856 yılında tanımlanmış ve epitelyal ve konnektif doku elementlerinin birbirinin içine geçerek oluşturduğu histolojik karakter nedeniyle 'silindroma' olarak adlandırılmıştır. 'Adenoid kistik karsinoma' terimi ise 1954 y1lında Ewing tarafindan tanımlanmıştır $(3,6)$. Lezyon, çoğunlukla kadınlarda ve 5 ve 6 . dekatlarda görülmektedir, bu vaka raporunda ise 69 yaşında bir erkek hastaya ait AKK olgusu sunulmuştur.

Tükürük bezlerinin AKK's1 yavaş gelişim göstermektedir fakat geç lokal rekürrens eğilimine sahiptir $(9,10)$. AKK baş-boyun bölgesi tümörlerinin \%10-15'ini oluşturmaktadır ve yaygın görülen bir tümör değildir. Lakrimal bezin en yaygın görülen tümörüdür, tükürük bezlerinin ise mukoepidermoid karsinomdan sonra en yaygın görülen ikinci tümörüdür (7). Hastaların sağ kalım süresi yeterince uzun olursa radikal eksizyon yapılması durumunda bile rekürrens açısından yüksek yatkınlık göstermektedir. $\mathrm{Bu}$ nedenle tedavisi oldukça zor bir neoplazmdır (11). Tümörün yavaş büyümesi nedeniyle, hastalar tedavi için başvurduklarında lezyonun birkaç yıldır var olmasıyla karakterizedir. Bunun dışında ağrı, fasiyal paralizi ve perinöral invazyon da AKK'nın karakteristik özelliklerindendir (3). $\mathrm{Bu}$ vakada da hastanın lezyonun birkaç yıldır var olduğunu belirtmesi, bukkal mukozasında şişlik, ağrı ve parestezi şikayetinin olması lezyon ön tanısı için belirleyici bulgulardı.
AKK'nın histolojik olarak kribriform, tubuler ve solid alt tipleri bulunmaktadır. Kribriform ve solid tipleri biyolojik olarak daha agresif yapı düşündürürken tubuler tip AKK'nın daha diferansiye patternini düşündürmektedir $(1,8)$. Bizim vakamız solid patterne sahip bir AKK olgusudur. Günümüzde AKK olgularının tedavisinde genel yaklaşım temiz ve geniş sınırlı rezeksiyon şeklindedir. Cerrahlar özellikle rejyonel sinirlerin çevresinde temiz sınırlar elde etmek için dikkatle yaklaşmalıdır. Cerrahi sonrasi radyoterapi neoplazinin lokal ve rejyonel kontrolünü sağlama olasılığını artırmaktadir.

\section{Sonuç}

Oral kavite kanserlerinin tespiti sıklıkla hastalarda şikayet oluşturup kliniğe başvurdukları dönemde olmaktadır. Özellikle malign karakterli lezyonlarda, sağ kalım süresinin uzatılması ve uzak bölgelere metastazın önlenmesi için lezyonların erken dönemde tanımlanması ve tedavi planının oluşturulması oldukça önemlidir. Bu nedenle ilk muayene sırasındaki doğru değerlendirme ve olasi taniların belirlenmesi bu vakaların tedavi başarısını etkileyecektir. AKK gibi tükürük bezi kaynaklı neoplazilerin yavaş ilerleyen fakat komșu yapılara agresif infiltrasyon, uzak metastaz ve rekürrens olasılıkları nedeniyle uzun dönem takipleri çok önemlidir. Şüpheli durumlarda erken dönemde biyopsi ve tedavi, sağ kalım süresi ve tedavide başarı oranı açısından önemlidir.

\section{KAYNAKLAR}

1. Harish K, Mangala Gouri SR. Adenoid cystic carcinoma of the parotid metastazing to liver: case report. BMC Cancer. 2004;4:41-5.

2. Ouyang DQ, Liang LZ, Zheng GS, et al. Risk factors and prognosis for salivary gland adenoid cystic carcinoma in southern china: A 25-year retrospective study. Medicine (Baltimore) 2017;96:e5964.

3. İnceoğlu B, Yakar EN, Şentürk $\mathrm{MF}$, et al. Mandibulada Adenoid Kistik Karsinoma: Olgu Sunumu. SDÜ Sağllk Bilimleri Enstitüsü Dergisi. 2015;6:84-6.
4. Özdoğan F, Özcan M, Selçuk A, et al. Dil kökü adenoid kistik karsinomu: Olgu sunumu. Med $J$ Bakırkoy. 2012;8:187-90

5. Bereket C, Şenyurt Ö, Koyuncu M et al. Sert damak yerleşimli, solid tip adenoid kistik karsinoma: Olgu sunumu. Turkiye Klinikleri $J$ Dental Sci. 2012;18:347-51.

6. Godge P, Sharma S, Yadav M. Adenoid cystic carcinoma of the parotid gland. Contemp Clin Dent. 2012;3:223-6.

7. Orhan K, Yüksel Y, Görür Dİ. Solid adenoid cystic carcinoma of the maxilla: a case report. Hacettepe Dishek Fak Derg. 2006;30:42-7. 
8. Kazancıoğlu HO, Çakır O, Ak G. Palatal Adenoid Kistik Karsinom. Turkiye Klinikleri J Dental Sci. 2015;21:65-70.

9. Tincani AJ, Del Negro A, Araújo PPC, Akashi HK, Martins AS, Altemani AM, Barreto G. Management of salivary gland adenoid cystic carcinoma: institutional experience of a case series. Sao Paulo Med Journal. 2006;124:26-30.

10. Ko JJ, Siever JE, Hao D, Simpson R, Lau HY. Adenoid cystic carcinoma of head and neck: clinical predictors of outcome from a Canadian centre. Curr Oncol. 2016;23:26-33.

11. Bahadir O, Livaoglu M, Ural A. Adenoid cystic carcinoma of the parotid gland: Anastamosis of the facial nerve with the great auricular nerve after radical parotidectomy. Indian $J$ Plast Surg. 2008;41:201-5 